\title{
Raynaud's phenomenon, vibration induced white finger, and difficulties in hearing
}

\author{
K T Palmer, M J Griffin, H E Syddall, B Pannett, C Cooper, D Coggon
}

Occup Environ Med 2002;59:640-642

See end of article for authors' affiliations

Correspondence to:

Dr K Palmer, MRC

Environmental

Epidemiology Unit,

Southampton General

Hospital, Southampton

SO16 6YD, UK;

ktp@mrc.soton.ac.uk

Accepted 12 March 2002
Background: An association has previously been reported between finger blanching and hearing difficulties, but only in workers with exposure to noise and hand transmitted vibration (HTV).

Aims: To explore the association in a community sample, including cases who lacked occupational exposure to noise or HTV.

Method: A questionnaire was mailed to 12606 subjects aged 35-64 years, chosen at random from the age-sex registers of 34 British general practices. Inquiry was made about years of employment in noisy jobs, lifetime exposure to HTV, hearing difficulties and tinnitus, and lifetime history of cold induced finger blanching. Subjects were classed as having severe hearing difficulty if they used a hearing aid or found it difficult or impossible to hear conversation in a quiet room. Associations of finger blanching with hearing difficulties and tinnitus were analysed by logistic regression.

Results: Among 8193 respondents were 185 who reported severe hearing difficulty and 1151 who reported finger blanching. After adjustment for age and years of work in noisy jobs, hearing difficulty was about twice as common in men and women who reported finger blanching, including those who had never been importantly exposed to noise and in those never exposed to HTV.

Conclusions: These data support an association between finger blanching and hearing loss, which is not explained by confounding occupational exposure to noise, and suggest that it may extend to causes of blanching other than vibration induced white finger. Further investigations are warranted to confirm the association and explore possible mechanisms, such as sympathetic vasoconstriction in the cochlea.
W orkers exposed to occupational sources of hand transmitted vibration (HTV) often suffer from hearing loss, as well as vibration induced white finger (VWF) and other features of the hand-arm vibration syndrome. Powered vibratory tools such as chain saws are noisy, and the association may simply reflect concomitant exposure to noise. But in several surveys of forestry workers, hearing thresholds were worse in men with finger blanching than in colleagues of similar age considered to have similar exposures to noise and vibration. ${ }^{1-4}$

Such findings have prompted the hypothesis that the sympathetic vasoconstriction observed in VWF affects cochlear

\section{Main messages}

- An association has previously been reported between finger blanching and hearing difficulties, perhaps as a result of sympathetic vasoconstriction.

- Earlier research involved workers who were exposed to hand transmitted vibration (HTV), so the findings may have been confounded by noise from the tools.

- If a vascular mechanism underlies the association, hearing problems ought to be linked with finger blanching, even when noise and vibration are absent.

- Data from this community survey support this association, and suggest that it occurs even in subjects who have never worked in noisy jobs or with vibratory tools.

\section{Policy implications}

- These findings need to be confirmed by further inquiry.

- If true, they provide a further reason for controlling exposures to HTV. blood flow, rendering the worker more vulnerable to noise induced sensorineural hearing loss.

One concern with this interpretation is the extent to which these occupational studies accounted for the confounding influence of noise. All were conducted in a setting where noise was invariably present; but a different approach would be to examine the risks of hearing impairment in subjects with non-occupational Raynaud's phenomenon, including those who have never worked in a noisy job. The association of hearing impairment with non-occupational causes of finger blanching, such as primary Raynaud's disease, has never been formally investigated, but the mechanism purported to underlie the excess of hearing difficulties-sympathetic vasoconstriction-is common both to VWF and other categories of Raynaud's phenomenon, as are several other processes (such as aggregation of platelets and hyperviscosity of blood) which may contribute to blanching episodes. Thus, an association between hearing loss and idiopathic Raynaud's phenomenon might be demonstrable even in the absence of significant noise exposure. On the other hand, no association would be apparent if the risk arose only from the combination of vasospasm and noise, or if it were specific to VWF as opposed to other causes of finger blanching.

We recently conducted a large postal survey of vibration and health, which enabled us to explore the relation of hearing loss to finger blanching according to exposure to noise and HTV.

\section{METHODS}

The study sample for the main survey comprised 21201 men and women of working age, chosen at random from the age-

Abbreviations: $\mathrm{Cl}$, confidence interval; HTV, hand transmitted vibration; $\mathrm{PR}$, prevalence ratio; VWF, vibration induced white finger 
Table 1 Prevalence of hearing difficulties and tinnitus in subjects with and without cold induced finger blanching

\begin{tabular}{|c|c|c|c|c|c|c|}
\hline & \multicolumn{3}{|c|}{ Severe hearing difficulty } & \multicolumn{3}{|c|}{ Persistent tinnitus } \\
\hline & $\begin{array}{l}\text { Never } \\
\text { blanched } \\
{ }^{*} \text { No. (\%) }\end{array}$ & $\begin{array}{l}\text { Ever blanched } \\
{ }^{*} \text { No. (\%) }\end{array}$ & tPR $(95 \% \mathrm{Cl})$ & $\begin{array}{l}\text { Never } \\
\text { blanched } \\
\text { *No. (\%) }\end{array}$ & $\begin{array}{l}\text { Ever blanched } \\
{ }^{*} \text { No. (\%) }\end{array}$ & tPR $(95 \% \mathrm{Cl})$ \\
\hline \multicolumn{7}{|l|}{ Men } \\
\hline All men & $71(2.4)$ & $35(8.0)$ & 2.2 (1.4 to 3.3 ) & $234(7.1)$ & $51(10.3)$ & $1.1(0.8$ to 1.5$)$ \\
\hline Never exposed to noise & $20(1.4)$ & $5(3.9)$ & $2.2(0.8$ to 5.9$)$ & 75 (4.5) & $10(6.8)$ & $1.4(0.7$ to 2.6$)$ \\
\hline Never exposed to HTV & $29(1.9)$ & $7(5.1)$ & $2.1(0.9$ to 4.7$)$ & $107(6.3)$ & $9(6.0)$ & 0.8 (0.4 to 1.5$)$ \\
\hline \multicolumn{7}{|l|}{ Women } \\
\hline All women & $42(1.9)$ & $12(2.9)$ & $1.4(0.8$ to 2.7$)$ & $92(3.5)$ & $25(5.0)$ & $1.4(0.9$ to 2.1$)$ \\
\hline Never exposed to noise & $29(1.6)$ & $10(3.1)$ & $1.9(1.0$ to 3.9$)$ & $60(2.8)$ & $15(4.0)$ & $1.4(0.8$ to 2.4$)$ \\
\hline Never exposed to HTV & $33(1.7)$ & $10(3.1)$ & $1.8(0.9$ to 3.6$)$ & 74 (3.3) & $12(3.1)$ & $0.9(0.5$ to 1.7$)$ \\
\hline
\end{tabular}

sex registers of 34 widely dispersed British general practices (163 general practitioners), and 993 members of the armed services. ${ }^{5}$ However, as hearing difficulties proved to be uncommon below age 35 years and in the armed services, ${ }^{6}$ the analyses in this paper relate to the 7335 men and 5271 women aged 35-64 years who were chosen from the general practices $(n=12606)$. Each subject was sent a postal questionnaire, followed if necessary by a reminder after five weeks.

We have provided details of the sampling, the content of the questionnaire, and the validity of our measuring instruments elsewhere. ${ }^{5-8}$ Questions of special relevance to the current analysis concerned the number of years of employment in noisy jobs where it was necessary to shout to be heard; lifetime exposure to HTV; hearing difficulties and persistent tinnitus; and lifetime history of cold induced finger blanching.

Information on exposure to HTV came from a closed question about use in the past week of 39 listed tools and machines, and from open questions about recent exposure to other sources and earlier exposures, both in work and in leisure, that were coded for relevance by an expert panel. ${ }^{5}$ Subjects were thus categorised according to their lifetime history exposure to HTV. They were also classed as having:

- "Severe" hearing difficulties if they used a hearing aid or reported that it was difficult or impossible to hear conversation in a quiet room ${ }^{6}$

- "Persistent" tinnitus if the symptom was present most or all of the time over the past year

- Finger blanching if they had ever had attacks in which any or all of their fingers suddenly became cold and numb and at the same time turned white or pale and which were sometimes cold induced. ${ }^{58}$

In addition, information was collected on age, sex, and smoking habits, and location of practice as potential confounding factors. However, smoking was discarded following a preliminary analysis in which no relation was found with hearing loss or tinnitus, ${ }^{6}$ and prevalence of finger blanching was found not to vary much by practice. Therefore, associations of finger blanching with hearing difficulties and tinnitus were analysed by logistic regression with adjustment for age, sex, and years of work in noise. The findings were summarised as prevalence ratios (PRs) with associated 95\% confidence intervals (CIs). These were derived from the corresponding odds ratios according to a formula proposed by Zocchetti and colleagues. ${ }^{9}$ Analysis was confined to subjects who provided full information on hearing loss or tinnitus and also on blanching and their exposures to noise and HTV.

\section{RESULTS}

Usable questionnaires were returned by 8193 (65\%) of those selected for study. Of these, 185 (2.3\%) reported severe hearing difficulty, 444 (5.4\%) persistent tinnitus, and 1151 (14.1\%) a history of cold induced finger blanching. However, 20 subjects with hearing difficulty and 32 with tinnitus failed to report on their exposure to noise, and were omitted from the respective analyses; five others with hearing difficulty and 10 with tinnitus did not answer the question on blanching and were also excluded.

Some expected relations were observed in the data. The prevalence of tinnitus (directly standardised to the age and sex distribution of the whole sample) was higher in subjects with severe hearing difficulties $(26.5 \%)$ than in those with minimal or no hearing difficulties in either ear (5.4\%); both symptoms were more common at older ages and in men compared with women. After adjustment for age, their prevalence also increased with the number of years spent in noisy jobs. For example, the risk of severe hearing difficulty was increased fourfold in men with longer than 10 years of noisy work compared with those exposed for less than a year.

Table 1 shows the associations of severe hearing difficulty and tinnitus with finger blanching. After adjustment for age and years of work in noisy jobs, hearing difficulty was approximately twice as common in men and women who reported cold induced finger blanching. Furthermore, the relation was apparent even in those who had never been importantly exposed to noise at work and in those never exposed to HTV. In contrast, no parallel association was found between blanching and tinnitus.

\section{DISCUSSION}

An association between finger blanching and hearing impairment has been reported previously, ${ }^{1-4}$ but always in the context of coincidental exposure to noise, and only for individuals considered to have VWF. The data from this study, however, support an association which is not explained by confounding occupational exposure to noise, and indicate that it may extend to causes of blanching other than VWF.

The data derived from a large geographically dispersed sample which had an occupational and age-sex distribution similar to that of 16-64 year olds from the general population, and which provided similar estimates of the prevalence of finger blanching and HTV to those from other British community surveys. ${ }^{5}$ Representativeness of response was also suggested by the similar prevalence of exposures and health outcomes in those who responded with and without a reminder (differential interest in the study might be expected to result in a higher prevalence of these parameters in early responders than in those who responded late).

One potential source of error was inaccuracy in the information supplied, but we consider that our measures of exposure and effect had a reasonable degree of validity. In a pilot study, we explored the accuracy with which the questionnaire ascertained exposures to HTV in subjects' current jobs, and found that reports were generally plausible ${ }^{7}$; 
previous community surveys which ascertained finger blanching using the same or similar questions found a predictive value of around $80 \%$ for Raynaud's phenomenon as judged by follow up medical interview ${ }^{10}$; self reports of moderate or worse difficulty in hearing based on the questions we used, corresponded to a measured hearing impairment of about 45 dB HL in the National Survey of Hearing ${ }^{11}$; and the expected relations were observed in the data between hearing impairment and tinnitus, and between our index of noise exposure and these auditory effects. Non-differential misclassification of the two health outcomes would tend to bias risk estimates towards the null value, and so cannot account for the pattern observed. Similarly, imprecision in the reported duration of workers' exposure to noise would weaken our ability to adjust for this factor as a confounder, but it would not explain the association between blanching and hearing difficulty in subjects who had never worked in a noisy job.

An association between self reports of blanching and hearing difficulty might arise as an artefact of general over reporting of symptoms, but the effect was specific to hearing difficulties and did not apply to tinnitus, which argues against this explanation.

The possibility that sympathetic vasoconstriction causes hearing impairment has been little explored hitherto. Further investigations are warranted to confirm our findings and to explore possible mechanisms. In particular, as our study was limited by relatively small numbers with severe hearing loss (in a survey planned only to cover working aged adults) and several of the confidence intervals in the table straddled one, the role of chance in the findings needs to be clarified. A first step might include an assessment of finger blanching in subjects with and without hearing loss on audiometric screening. Alternatively, evidence of hearing impairment might be sought in subjects with non-occupational Raynaud's phenomenon.

\section{ACKNOWLEDGEMENTS}

This study was made possible by a grant from the Health and Safety Executive. We thank the Royal College of General Practitioners, the Primary Care Rheumatology Society, and the 34 general practices who also supported the research.

\section{Authors' affiliations}

K T Palmer, H E Syddall, B Pannett, C Cooper, D Coggon, MRC Environmental Epidemiology Unit, Community Clinical Sciences,

University of Southampton, UK

M J Griffin, Institute of Sound and Vibration Research, University of Southampton

\section{REFERENCES}

1 Pyykko I, Starck J, Farkkila $M$, et al. Hand-arm vibration in the aetiology of hearing loss in lumberjacks. Br J Ind Med 1981;38:281-9.

2 Pyykko I, Koskimies K Starck J, et al. Risk factors in the genesis of sensorineural hearing loss in Finnish forestry workers. Br J Ind Med 1989;46:439-46.

3 Iki M, Kurumatani N, Hirata K, et al. An association between Raynaud's phenomenon and hearing loss in forestry workers. Am Ind Hyg Assoc J 1985;46:509-13.

4 Miyakita T, Miura H, Futatsuka M. Noise-induced hearing loss in relation to vibration-induced white finger in chain-saw workers. Scand J Work Environ Health 1987; 13:32-6.

5 Palmer KT, Coggon DN, Bendall HE, et al. Hand-transmitted vibration: occupational exposures and their health effects in Great Britain. HSE
Contract Research Report 232/1999. Sudbury: HSE Books, 1999.

6 Palmer KT, Griffin M, Syddall HE, et al. Occupational exposure to noise and the attributable burden of hearing difficulties in Great Britain. Occup Environ Med 2002;59:634-9.

7 Palmer KT, Haward BM, Griffin M, et al. The validity of self-reported occupational exposures to hand-transmitted and whole-body vibration. Occup Environ Med 2000;57:237-41.

8 Palmer KT, Griffin M, Syddall H, et al. The prevalence of Raynaud's phenomenon in Great Britain and its relation to hand-transmitted vibration: a national postal survey. Occup Environ Med 2000:57:448-52.

9 Zocchetti C, Consonni D, Bertazzi PA. Estimation of prevalence ratios Zocchetti C, Consonni D, Bertazzi PA. Estimation of prevalenc
from cross-sectional data. Int J Epidemiol 1995;24:1064-5.

10 Heslop J, Coggon D, Acheson ED. The prevalence of intermittent digital ischaemia (Raynaud's phenomenon) in a general practice. J $R$ Coll Gen Pract 1983;33:85-9.

11 Davis AC. The prevalence of hearing impairment and reported hearing disability among adults in Great Britain. Int J Epidemiol 1989:18:911-17. 